\title{
LVII. On constructing electric columns
}

\section{B.M. Forster Esq.}

To cite this article: B.M. Forster Esq. (1816) LVII. On constructing electric columns, Philosophical Magazine Series 1, 47:216, 265-266, DOI: 10.1080/14786441608628460

To link to this article: http://dx.doi.org/10.1080/14786441608628460

曲 Published online: 27 Jul 2009.

Submit your article to this journal

III Article views: 2

Q View related articles $₫$ 
that the nitric acid was not in such great excess had a sufficient quantity of water been employed, and that the muriatic acid is not of so much consequence in the formation of protoxide of antimony, since the whole of the eleven fluid ounces there prescribed might have been omitted.

I remain, sir,
Long Acre, April 17, $1810 . \quad$ Your obedient servant,
Jos. Hume.

"To Dr. Latham, \&̊c. $89 c .8 \%$

"Sir,-A very simple and, I believe, effectual method of preparing tartarized antimony occurred to me yesterday, which I nim anxious to present to you lest I should be anticipated unfairly by any other experimentalist.

"I shall not at present take up more of your time than to state the following sketch of the process.

"The common black sulphuret of antimony is boiled with nitrons acid largely diluted with water. This produces an oxide of antimony which, after being properly washed, is to be boiled with supertartrate of potass and distilled water. The operation is then to be finished in the usual manner by cvaporation and crystallization.

"I have the honour to be, Sir, \&c.
Long-Acre, Jam. 21, 1814.

LVII. On constructing Electric Colunins. By B. M. Forster, Fisq.

To Mr. Tilloch.

$\mathrm{S}_{\mathrm{iR}},-I_{\text {Have lately formed an electric column, by a process }}$ somewhat different from any hitherto adopted, I believe; and imagining that it may prove a very convenient one, I wish by means of your publication to make it known, hoping that those persons who are interested about this curious instrument will make experiments to determine the comparative power of a column formed by this method, and one made according to Mr. De Luc's original plan.

Not being able easily to procure manganese in a finely-powderet state, which I understand has been matle use of instead of plaics of zinc, I was desirous of trying the effect of zinc very finely powdered; and having obtained some of this substance pulverized, in order to get the very fine particles I sifted it through muslin, then mixed it with a solution of common glue and some moist sugar. This mixture I laid on the back of Duth- 
Dutch-gill embossed paper with a brush, by which method a triple dise was olutained, consisting of Dutch metal (copper), paper and zinc. Perhaps some one may be able to describe the exact method of unaking the Dutch-gilt paper; if so, I shall esteem it a favour to be informed of it. I understand that the metal is formed of copper principally, but of what other substance is unknown to me. It apyears to me that a considerable advantage may be gained by the above-mentioned process, both in time and labour, as these plates or discs are much more easily punched ont than plates of zinc, and the placing them in a column is also much more easily done on account of there being only one kind of disc, therefore less chance of a mistake is likely to occur in the disposition of them. If paper with silverleaf laid on it, as described in Philosophical Magazine, vol. xxxv. p. 205 (March 1810), were used instead of Dutch-gilt paper, the effect would probably be stronger, and still more so if dises of silvered paper and discs of paper with powdered zinc were used, as the paper would then be more capable of inbibing moisture from the atmosphere than when both sides are coated with metal. $\Lambda$ s the gold-leaf electrometer, commonly used for experiments with the electric column, is rather an expensive one, and troublesome on account of the delicacy of the goldleaves, it may not be unacceptable to many of your readers to be informed, that a metal-leared electrometer of great sensibility may at a very reasonable cost be made, with a small lamp-glass fitted up with a makogany top and base; the leaves are to be made of Dutch metal fastened to a thick piece of brass wire or slip of wood fixed into a piece of cork (which is to be glued on to the wooden cap); slips of tin-foil or Dutch-metal are to be piated on two opposite parts of the glass cylinder as usual.

Electroncters made with Dutch-metal as above mentioned, are strongly affected by a person's finger being placed on them, if he suddenly rise from a chair (with a horse-hair seat) and stand upon a dry fire-hearth, the electric effects being produced by his woollen clothing rubbing against the horse-hair chair.

A dry fire-hearth being found to be a very good insulator, I freguently make use of it instead of a stool with glass legs. Should it be found that $\approx$ inc dust laid on, as in the foregoing nccount, does answer the purpose desired; this method may be worthy of the attention of the philosophical-instrument-maleers, as they might probably find a sale for this (as it may be called) electrical paper. If zinc could be procured in as thin laves as silver or Dutch-metal, it probably would be better for eleclric columus than zinec dust.

April 1?, 1816 .

B. M. Forster.

LVIII. Re : 